Impaired endothelium-dependent vasodilatation among workers with IGT may decrease heat dissipation by conduction, convection, radiation, and sweat evaporation and may pose a risk to develop HRI.

\section{OCCUPATIONAL HEAT ILLNESS IN OUTDOOR WORKERS BEFORE AND AFTER THE IMPLEMENTATION OF A HEAT STRESS AWARENESS PROGRAM}

${ }^{1}$ Ronda B McCarthyy; ${ }^{2}$ Francis Shofer, ${ }^{2}$ Judith Green-McKenzie. ${ }^{1}$ The City of Waco, Concentra; Waco, Texas, U.S. ${ }^{2}$ The University of Pennsylvania, Philadelphia, PA, U.S

\subsection{6/oemed-2018-ICOHabstracts. 1430}

Introduction Heat Stress is an occupational hazard expected to increase in severity and breadth with climate change. Workers exposed to heat and hot environments can have increased injuries, exacerbation of disease, reduced productivity, and heat illness resulting in death. Strategies to respond are mitigation policies and preparedness. The National Institute of Occupational Safety and Health's (NIOSH) Revised Criteria for a Recommended Standard, Occupational Exposure to Heat and Hot Environments outlines training for and medical surveillance and research of worker populations exposed.

Methods Heat illness and worker's compensation costs before and after the implementation of a Heat Stress Awareness Program (HSAP) were evaluated retrospectively in a cohort of outdoor municipal workers from 2010-2016. The HSAP brought training and medical surveillance to at risk workers as outlined in NIOSH's Criteria for a Recommended Standard Occupational Exposure to Heat and Hot Environments.

Results 526 outdoor workers met inclusion criteria. Prior to implementation of the HSAP the occupational heat illness rate was $3 \%$, this decreased to $1 \%$ the first three years of the program and less than $1 \%$ the last two years. Workers with heat illness were more likely to be extremely obese $(p<0.0003)$ and more likely to have two or more heat illness risk factors. Total worker's compensation costs decreased approximately $50 \%$ per illness or less than prior to HSAP.

Discussion Training, determining fitness for duty and regular medical monitoring prior to work in a hot environment may decrease frequency of occupational heat illness and occupational medical care costs in exposed workers. This study supports NIOSH's Occupational Exposure to Heat and Hot Environments' promulgation into U.S. law which can provide protection to vulnerable U.S. workers and may provide valuable guidance to the unknown numbers that will be added to the climate-vulnerable population as the global temperature continues to rise.

\section{TRANSITION OF GOVERNMENTAL GUIDELINES TO PREVENT HEAT STROKE AT WORK IN JAPAN}

${ }^{1} \mathrm{C}$ Nagano*, 'N Gonmori, ${ }^{2} \mathrm{~S}$ Kawanami, 'S Horie. 'Department of Health Policy and Management, University of Occupational and Environmental Health, Japan; ${ }^{2}$ Occupational Health Training Centre, University of Occupational and Environmental Health, Japan

\subsection{6/oemed-2018-ICOHabstracts. 1431}

Introduction In Japan, the prevention of fatal heat strokes at work has become more important along with the global warming.
Methods This research introduces the transition of methods to prevent heat stroke at workplaces in Japan within the latest 20 years.

Results The number of fatal heat stroke at work in Japan had been less than 20 until 1993; however, it exceeded 20 in 1994 and in 1995, consecutively because of the heat wave attack during summer. Therefore, in 1996, the guideline on prevention of heat stroke at work was formulated and publicised by the Labour Standard Bureau, Ministry of Health, Labour and Welfare. It advocated fundamental methods for the prevention of heat stroke such as working environment management, work management, health management and occupational health education at workplaces exposed to heat stress. Besides, the government started to announce the number of compensated cases of heat strokes every year. In 2005, another guideline was issued advocating the measurement of WBGT at the workplaces and the utilisation of the value for appropriate countermeasures. In 2009, the first guideline was totally revised by adding many new contents: the utilisation of WBGT, the promotion of heat acclimation, the method of desirable water and salt intake, the consideration for vulnerable persons with underlying diseases and the management of daily physical conditions. In addition, due to the impact of the Great East Japan Earthquake in 2011, nuclear power generation in Japan was temporarily suspended, and the need for the development of measures against heat stroke that did not use electric power as much as possible had increased, from the viewpoint of energy saving. Therefore, sports drinks and oral rehydration, salt candy, cool best to cool the body, clothing of quick-drying/cool feeling materials, etc. have started to be sold and widely spread.

Discussion Although the motivation for the prevention of heat strokes have spread rapidly during the last 20 years, according to the guidelines formulated by the government, the number of mortality often exceeds 20 , including 47 in the historically worst year of 2010. While easy and inexpensive devices to prevent heat stroke such as nutritional supplements and special wears have become widespread, it is important to verify its effectiveness in an objective manner and to standardise the definition of devices able to cool down the body heat.

\section{Toxicology of Metals}

\section{METHYLTRANSFERASE GENE EXPRESSION AS POSSIBLE MEDIATOR OF THE EFFECTS OF ARSENIC EXPOSURE: AN EPIGENETIC STUDY IN FOUNDRY WORKERS}

1,2 M Bonzini* ${ }^{2}$ L Angelici, ${ }^{2} \mathrm{C}$ Pagliuca, ${ }^{2} \mathrm{M}$ Carugno, ${ }^{3} \mathrm{P}$ Apostoli, 1,2 $\mathrm{AC}$ Pesatori, ${ }^{2} \mathrm{~V}$ Bollati. ${ }^{1}$ Occupational Medicine Unit, Fondazione IRCCS Cà Granda - Ospedale Maggiore Policlinico, Milan, Italy; ${ }^{2}$ EPIGET Lab, Department of Clinical Sciences and Community Health, University of Milan, Italy; ${ }^{3}$ Department of Experimental and Applied Medicine, University of Brescia, Brescia, Italy

\subsection{6/oemed-2018-ICOHabstracts. 1432}

Introduction Arsenic is an environmental carcinogen that undergoes methylation while metabolised. Subsequent intracellular methyl groups depletion can decrease global DNA methylation, facilitating carcinogenesis. On the other hand, hypermethylation in promoter regions of tumour suppressor genes related to arsenic exposure has been observed in-vivo. The effects of arsenic on enzymes regulating gene-specific methylation (DNA-methyltransferases) have not been fully 